\title{
Estudio del Lenguaje de los Nativos Digitales: Una Nueva Forma de Redacción
}

\section{Study of Digital Natives' Language: A New Form of Writing}

Pepita Alarcón-Parra ${ }^{a}$, Javier Romero Guillen ${ }^{b}$, Giovanny Alarcón Parra

\author{
INFORMACIÓN DEL \\ ARTÍCULO \\ Fecha de recepción:10 de febrero del \\ 2017 \\ Fecha de aceptación: 22 de marzo del \\ 2017
}

\footnotetext{
${ }^{a}$ Centro de Investigación en Modelos de Gestión y Sistemas Informáticos CIMOGSYS, Grupo de Investigación

e Interacción en Tecnologías de la Comunicación IITC, Escuela de Diseño Gráfico, Facultad de Informática y Electrónica, Escuela Superior Politécnica de Chimborazo Riobamba - Ecuador.

E-mail: palarcon@espoch.edu.ec
}

${ }^{b}$ Grupo de Investigación e Interacción en Tecnologías de la Comunicación IITC, Escuela de Diseño Gráfico, Facultad de Informática y Electrónica, Escuela Superior Politécnica de Chimborazo Riobamba - Ecuador

E-mail: jromero@espoch.edu.ec

\begin{abstract}
Resumen
Este trabajo se centró en el análisis objetivo y detallado, basado en la revisión bibliográfica y teórica que permita comprender la evolución y transformación de la generación de una nueva forma de redacción de mensajes que emplean los nativos digitales para comunicarse. Se diseñó un cuestionario validado por expertos, tomando como objeto de investigación a los estudiantes de los institutos de educación media de la ciudad de Riobamba, los datos obtenidos fueron procesados mediante estadística descriptiva. El método de investigación, análisis documental de las teorías, definiciones existentes y preexistentes en torno al término "nativo digital" arroja datos sobre sus habilidades comunicativas desarrolladas y sus particularidades más representativas y asimilación de otros soportes ajenos a los digitales los define como estudiantes multitarea personas que utilizan la información de forma instantánea, que prefieren utilizar gráficos al texto, los referidos mensajes visuales son utilizados en alto porcentaje por los denominados nativos digitales.
\end{abstract}

Palabras Clave

Nativos digitales, lenguaje, comunicación visual, hipertextualidad, habilidades comunicativas.

Clasificación JEL: D83. 


\section{Estudio del Lenguaje de los Nativos Digitales: Una Nueva Forma de Redacción}

\section{Study of Digital Natives' Language: A New Form of Writing}

Pepita Alarcón-Parra ${ }^{a}$, Javier Romero Guillen ${ }^{b}$ Giovanny Alarcón Parra ${ }^{c}$

\footnotetext{
${ }^{c}$ Docente de la Facultad de Informática y Electrónica, miembro del Grupo de Investigación en Modelos y Sistemas de Gestión IMSGS, Escuela Superior Politécnica de Chimborazo ESPOCH Director del Centro de Investigación en Modelos de Gestión y Sistemas Informáticos CIMOGSYS, Riobamba -Ecuador. Ingeniero en Gestión de Procesos, Máster en Dirección Estratégica, especialidad: Gerencia, orientación Gestión Integrada de Medio Ambiente Calidad y Prevención. Docente politécnico:

E-mail:giovanny_alarcon@cimogsys.com
}

\begin{abstract}
This work focuses on an objective and detailed analysis of a new form of message writing that digital natives use for communication. The analysis is based on a bibliographical and theoretical revision that allows the understanding of the generation's evolution and transformation. A questionnaire was designed and validated by experts; it purported to investigate secondary education students of the city of Riobamba; the data obtained by the questionnaire were processed through descriptive statistics. The research method, the documentary analysis of the existing and preexisting theories, the definition of the term digital native reveal data about the communicative abilities they developed. Their more representative peculiarities and their assimilation of non-digital supports define digital natives as multitasking students who use information instantly. They prefer to use graphics rather than text. The so-called digital natives use a high percentage of visual messages.

Keywords

Digital Natives, language, visual communication, hypertext, communication skills.

JEL Classification: D83.
\end{abstract}




\section{Introducción}

Las tecnologías de la información y las comunicaciones (TICs) han modificado los hábitos de comunicación en la sociedad, generándose nuevos lenguajes, formas y medios de transmitir información, estos conceptos exigen una perspectiva gnoseológica apropiada con enfoques diferentes como la aproximación a los patrones de consumo y hábitos de uso de internet, videojuegos y celulares de Henríquez, Patricia (2012), el nuevo sentido de relación entre ciencia, tecnología y cultura en un nuevo estatus: el de dimensión estructural de las sociedades contemporáneas que argumenta MartínBarbero (2006) o los cambios en las tecnologías descrito por Bijker, Hughes \& Pinch (1987) en su teoría de la construcción social de la tecnología.

Según la tecnología ha evolucionado, también han ido apareciendo nuevas formas de comunicación interpersonal, mediante los medios que se han ido desarrollando en el internet; es así, que los avances tecnológicos han dado lugar a la aparición de ciertos términos de acuerdo a cada generación, entre los cuales han aparecido los "emigrantes tecnológicos", los mismos que tratan de adaptarse a las nuevas tecnologías, mientras que las personas de hoy, que han nacido rodeados de ordenadores, video juegos, dispositivos móviles y herramientas de la era digital; se han identificado como "nativos digitales", término que fue acuñado por Prensky (2001).

Los nativos digitales que manejan las tecnologías de la información y la comu- nicación como: WhatsApp, Facebook, Twitter, YouTube, Skype y otros, han generado un nuevo lenguaje o llegado a modificar el lenguaje como era conocido, ya que utilizan anglicismos $($ casa $=k s a)$, con la combinación de los emoticones $\left(:\right.$ * $^{*}$ beso $)$ y el uso de vulgarismos del idioma inglés (ea - each en inglés - cada uno en español). Este tipo de lenguaje sólo lo utilizan para comunicarse mediante dispositivos de comunicación (ordenadores y móviles) que tienen acceso a internet, logrando transmitir sus mensajes destinados a personas que conocen dichos términos, de forma rápida y oportuna, rompiendo las barreras de las distancias, dicho fenómeno ya lo detecto Prensky (2001) cuando menciona en su artículo Digital Natives Digital Immigrants que los nativos digitales hacen uso de un nuevo lenguaje denominándolo entirely new language.

Algunos de los rasgos en los mensajes que se envían los referidos nativos digitales, poseen ciertas tendencias en la redacción lingüística al momento de escribir, ya sea eliminando o añadiendo otros textos.

En esta investigación se realizó un análisis de las nuevas formas que los nativos digitales emplean para comunicarse, determinando la estructura del lenguaje empleado en base a emoticones, anglicismos y vulgarismos del idioma inglés, con el objetivo de generar un lenguaje general para las personas inmersas en los distintos medios de comunicación con acceso a internet, este estudio será la base de muchos otros para mejorar la comunicación visual de mensajes desti- 
nado a este target desde la perspectiva publicitaria hablamos de un cambio de paradigmas ya que nuestro lenguaje es cada vez más visual y posee sus propias características, un código directo y de fácil interpretación, permitiendo que sea universal el uso del ícono en un mundo cada vez más globalizado.

\section{Metodología}

Se realizó un análisis documental y contrastado para determinar la existencia de rasgos sobre las competencias y habilidades de los "nativos digitales".

La población de interés para la investigación fueron los estudiantes de los colegios de la ciudad de Riobamba, empleando el método inductivo para la investigación y el análisis de la información recopilada de una muestra de cursantes del bachillerato.

Para el cálculo de la muestra, se tomó la fórmula para poblaciones finitas de Olivares (2006), permitiendo implementar como fuente de información secundaria las encuetas a la muestra calculada de 380 estudiantes, de una población 35000 (Ministerio de Educación, 2014).

El diseño de la encuesta validado por expertos y analizado mediante estadística descriptiva se dividió en dos enfoques: 1 . Análisis de las preferencias de los medios de comunicación y 2 . Análisis del código que emplean para transmitir sus mensajes.

Posteriormente se procesó la información recopilada y se elaboraron gráficos de tipo pastel, sobre los que se interpreta- ron los resultados alcanzados.

\section{Discusión}

En este marco de ideas, las preguntas que orientan el estudio cubren dos ámbitos: Indagar las características sicológicas y de competencias basados en las siguientes variables: el uso, forma de comunicarse, tipo de comunicación y el tipo de trabajo que realiza, lo que permite identificar de mejor manera a los nativos digitales. Luego se estudian las preferencias de comunicación de este grupo basados en tópicos como: preferencias de los medios de comunicación, tipo de acceso, uso de mensajes visuales y códigos que emplean para transmitir sus mensajes.

\section{EI nativo digital, competencias $y$ habilidades}

En la actualidad el ser humano está frente a dos mundos: uno digital y otro analógico, razón por la cual ha podido desarrollar competencias y habilidades nuevas, sin perder las que forman parte específica de su propia naturaleza, pudiéndose observar nuevas maneras de evolución de la humanidad. El término nativos digitales (digital natives), como se expuso anteriormente, fue desarrollado por Marc Prensky, en un ensayo titulado "La muerte del mando y del control", donde los identifica con aquellas personas que han nacido en la era digital y son usuarios permanentes de las tecnologías, con una habilidad consumada ya que argumenta que los patrones de pensamiento han cambiado en comparación a los que no pertenecemos a este grupo. 
Los nativos digitales satisfacen sus necesidades de entretenimiento, diversión, comunicación, información y trabajo con el uso de las TIC's, absorbiendo rápidamente la información multimedia de imágenes y videos, igual o mejor que si fuera texto; consumiendo datos simultáneamente de múltiples fuentes y esperando respuestas instantáneas; se mantienen comunicados permanentemente, siendo parte integral de sus vidas.

Entre las características que menciona Oblinger \& Oblinger (2005) tenemos a una comunicación visual intuitiva, con fuertes habilidades visoespaciales y capacidad para integrar lo virtual con el mundo físico. Reforzada por Fleming (2009), se conoce como "Ciber-esfera" al espacio íntimo de los jóvenes con su forma de vida, ya que cada joven construye su propio espacio o mundo, donde se pueden evidenciar o intercambiar diferentes niveles de intimidad y confianza.

Los nativos digitales manejan distintos canales de comunicación simultáneos y trabajan mejor en red como lo menciona Tapscott (1998) comunicación con un amplio espectro de usuarios en red, además desean recibir información de forma ágil e inmediata y, por ende, satisfacción y recompensas próximas tal como lo expone Sánchez \& Castro (2014) en su artículo "Cerrando la brecha entre nativos e inmigrantes digitales a través de las competencias informáticas e informacionales".

Las competencias de los nativos se analizó en base a cuatro enfoques: el uso, forma de comunicarse, tipo de comunicación y el tipo de trabajo que realiza basados en las características encontradas en la investigación bibliográfica y teórica. Logrando determinar que mediante el uso de ordenadores optimizan su tiempo, ya que realizan varias tareas a la vez, reemplazando la comunicación tradicional con el uso de imágenes, abreviaturas y otros símbolos para comunicarse mediante los distintos medios de comunicación que están conectados a la red, como se detalla en la Tabla 1. 
Tabla 1.

Competencias de los nativos digitales

\begin{tabular}{|c|c|c|c|c|}
\hline & Uso & Texto & Comunicación & Trabajo \\
\hline $\mathbf{C}$ & $\begin{array}{l}\text { Hacen varias } \\
\text { cosas al mismo } \\
\text { tiempo. }\end{array}$ & $\begin{array}{l}\text { Acceso } \\
\text { hipertextual en vez } \\
\text { del lineal. }\end{array}$ & $\begin{array}{l}\text { Manipulan } \mathrm{y} \\
\text { envían fotos digitales. }\end{array}$ & $\begin{array}{l}\text { Prefirieren } \\
\text { los formatos } \\
\text { gráficos a los } \\
\text { textuales. }\end{array}$ \\
\hline $\mathbf{E}$ & Utilizan & Utilizan & Manejan & Destacan la \\
\hline $\mathbf{T}$ & $\begin{array}{l}\text { ordenadores para } \\
\text { crear videos, } \\
\text { presentaciones } \\
\text { multimedia, música, } \\
\text { blogs, etc. }\end{array}$ & $\begin{array}{l}\text { imágenes para } \\
\text { remplazar texto } \\
\text { generando una } \\
\text { modernización de los } \\
\text { ideogramas. }\end{array}$ & $\begin{array}{l}\text { distintos canales de } \\
\text { comunicación } \\
\text { simultáneos. }\end{array}$ & $\begin{array}{l}\text { inmediatez en sus } \\
\text { acciones y en la } \\
\text { toma de } \\
\text { decisiones. }\end{array}$ \\
\hline $\mathbf{A}$ & \begin{tabular}{l}
\multicolumn{3}{c}{ Prefieren los } \\
juegos al trabajo \\
serio.
\end{tabular} & $\begin{array}{l}\text { Remplazan } \\
\text { palabras con } \\
\text { abreviaturas. }\end{array}$ & $\begin{array}{l}\text { Navegan } \\
\text { fluidez. }\end{array}$ & $\begin{array}{l}\text { Trabajan } \\
\text { mejor en red. }\end{array}$ \\
\hline
\end{tabular}

\section{¿A quién se le considera como Nativo Digital?}

Los autores como John Palfrey y Urs Gasser (2008), codirectores del Grupo de Investigación Internacional Digital Natives, consideran que no todos los jóvenes comprendidos en el marco de edad que engloba la calificación de Mark Prensky, pueden considerarse "nativos digitales", pues deben compartir una cultura global, no por edad, sino por sus prácticas en el uso de las Tecnologías de la Información y la Comunicación (TICs) y las huellas que estas tienen en su vida. Puede afirmarse que el nativo digital actúa en una realidad híbrida, en la que ya no es posible discriminar los ámbitos analógico y digital.
Una de las características preponderantes del joven de hoy y por lo tanto, "nativo digital", en su forma de relacionarse, es congeniar con aquel que esté en el mismo nivel comunicativo; es decir que pertenezcan a su mismo círculo en cuanto a las experiencias con el uso de las TICs, ya que usan códigos y sistemas de comunicación que viabilizan un tipo de relación legítimo. Para esos jóvenes el reconocimiento, el respeto y la relevancia, aparecen como elementos capitales para poder ser escuchados, para que la comunicación sea eficaz.

Tapscott (1998) menciona: "algunas características de los nativos digitales, como la independencia que desarrollan, pues adoptan un papel activo en la 
búsqueda y creación de la información; su franqueza emocional e intelectual, ya que al conectarse a internet se exponen a sí mismos..., de manera que su inclusión social, con el uso de internet, pasan de una orientación nacional a una global. La libertad de expresión y las opiniones definidas, el entorno.

Esta generación va siempre un paso por delante de los creadores de software y productores de contenido de la Web, pues siempre están buscando la forma de hacer mejor las cosas y con inmediatez. Los chicos y chicas de la era digital esperan que las cosas sucedan rápidamente, porque es así como suceden en el mundo actual; autenticidad y confianza, a pesar de que en Internet se pueden utilizar identidades falsas o la información puede ser engañosa o inservible, la Generación Net tiene muy en cuenta la fuente de dónde procede.

Según pudo determinarse en la investigación documental realizada, puede afirmarse que el nativo digital tiene nuevas características psicológicas, que pueden observarse en la Tabla 2 (Datos psicológicos de los nativos digitales).

Tabla 2.

Datos psicológicos de los nativos digitales

\begin{tabular}{|c|c|c|c|c|}
\hline & Uso & & & \\
\hline $\mathbf{S}$ & $\begin{array}{l}\text { El uso de } \\
\text { juegos electrónicos } \\
\text { generaron algunas } \\
\text { habilidades } \\
\text { cognitivas y de una } \\
\text { nueva estructura } \\
\text { neuronal en los } \\
\text { individuos. }\end{array}$ & $\begin{array}{l}\text { a un entorno } \\
\text { altamente } \\
\text { tecnificado. }\end{array}$ & $\begin{array}{l}\text { En su niñez han } \\
\text { construido sus } \\
\text { conceptos de espacio, } \\
\text { tiempo, número, } \\
\text { causalidad, identidad, } \\
\text { memoria y mente a } \\
\text { partir de los objetos } \\
\text { digitales que le rodean. }\end{array}$ & $\begin{array}{l}\text { El } \\
\text { crecimiento en este } \\
\text { entorno tecnológico } \\
\text { puede haber } \\
\text { influido en la } \\
\text { evolución del } \\
\text { cerebro de aquellos } \\
\text { individuos. }\end{array}$ \\
\hline & \multicolumn{4}{|c|}{$\begin{array}{l}\text { Su actividad con la tecnología configura sus nociones sobre lo que es la } \\
\text { comunicación, el conocimiento, el estudio/aprendizaje e, incluso y sus valores personales. } \\
\text { Prosperan con la satisfacción inmediata y bajo recompensas frecuentes. Prefieren los juegos } \\
\text { al "trabajo serio" }\end{array}$} \\
\hline
\end{tabular}

Los nativos digitales presentan un dominio de los medios de producción digital, aprovechando las tecnologías para incrementar sus capacidades de conocimiento, creativa y de difusión; que surgen de lo que se conoce como la globalización, ya que entienden el mundo como su única frontera, haciendo uso de la red con tendencia socializadora, en la que lo digital es parte primordial de sus vidas. 
Pueden también distinguirse a los nativos digitales como individuos que utilizan la información de forma rápida, en paralelo y multitarea, utilizando la red como fuente de información efectiva, prefieren los gráficos al texto, necesitan de una gratificación instantánea y eso puede ser observado en la preferencia que tienen por la interacción del juego en el trabajo.

\section{Relacionados con las preferencias de los medios de comunicación.}

Entre las preferencia de los medios de comunicación con más aceptación, según puede observarse en la Figura 1 que aparece a continuación, están los siguientes: whatsapp, con una aceptación del $40 \%$; el Facebook Messenger, con un 30\% y los porcentajes restantes se distribuyeron entre otros dos: Skype y Line.

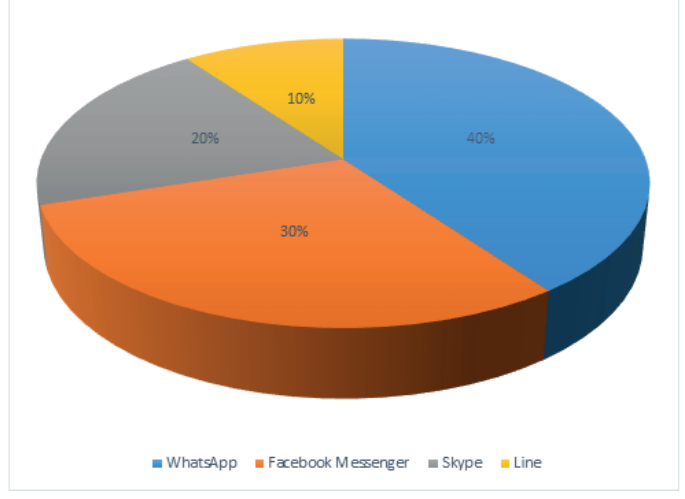

Figura 1. Preferencia de medios de comunicación. Encuesta sobre la preferencia de medios de comunicación.

Como se observa, la mayoría de los estudiantes hacen uso de whatsapp como medio para comunicarse con los demás. Cabe recalcar que los estudiantes para poder tener acceso a estos medios utilizan una conexión a WIFI; además, algunos poseen un plan de datos como se muestra a continuación.

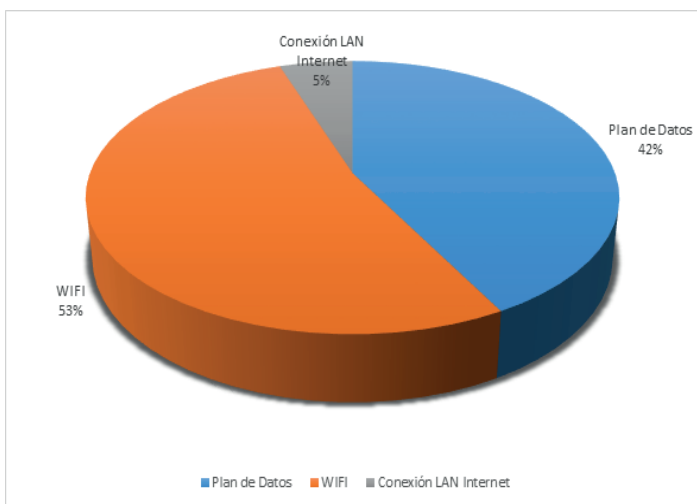

Figura 2. Tipo de acceso. Encuesta preferencia de medios de comunicación.

2. Relacionados con los códigos que emplean para transmitir sus mensajes.

Se evidenció que el 97\% de los estudiantes utiliza algunos de estos códigos visuales: abreviaturas, anglicismos o emoticones, mientras que apenas el 3\% indicó que no utiliza ninguno de ellos.

Estos datos muestran la importancia que tiene el uso de códigos de comunicación entre los jóvenes, según puede apreciarse en la Figura 3.

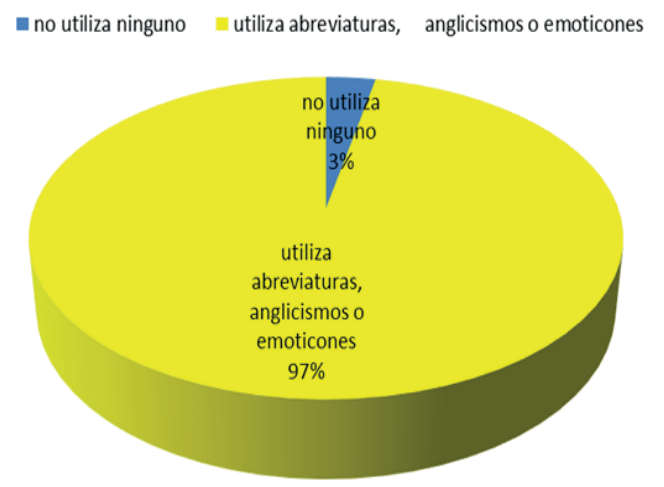

Figura 3. Uso de mensajes visuales. Encuesta "Análisis del código que emplea para transmitir sus mensajes". 
En cuanto a los códigos que más utilizan los estudiantes, son: las abreviaturas, con el $47 \%$ del total, seguido por los emoticones (25\%). El 18\% de los encuestados indicó que utilizan esos códigos por igual $\mathrm{y}$, finalmente, el $10 \%$ utiliza más los anglicismos.

Estos resultados indican una diferencia notable de las abreviaturas como el código visual más utilizado entre los jóvenes.

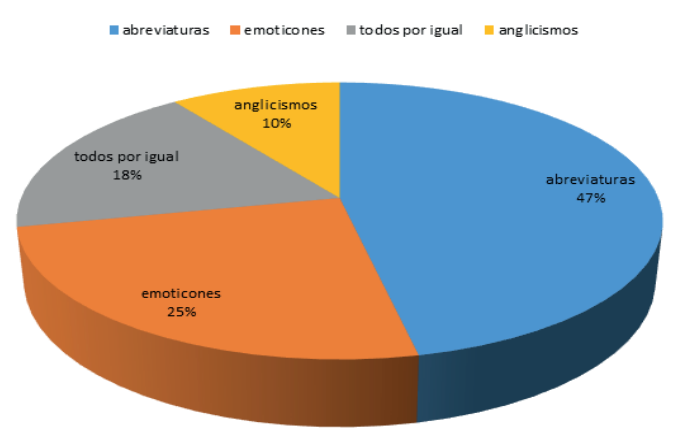

Figura 4. Código que emplea para transmitir sus mensajes. Encuesta "Análisis del código que emplea para transmitir sus mensajes".

\section{Conclusiones}

1. Se determinaron rasgos claros sobre las competencias y habilidades de los "nativos digitales", los que permiten definirlos como personas que utilizan la información de forma instantánea, en paralelo y multitarea, que prefieren utilizar gráficos al texto, el uso de redes para comunicarse con sus semejantes, precisan de una gratificación instantánea, usan sus ordenadores para crear videos, presentaciones multimedia, música, blogs y otros y son estudiantes multitarea; o sea, que realizan varias actividades al mismo tiempo y que prefieren la diversión al trabajo.

2. El 97\% de los estudiantes encuestados afirmó utilizar alguno de los nuevos códigos visuales, como son: abreviaturas, anglicismos o emoticones, mientras que apenas el 3\% indicó que no utiliza ninguno de ellos para comunicarse.

3. Puede afirmarse, por tanto, que el uso de códigos visuales conforman un lenguaje general para las personas inmersas en el uso de los medios de comunicación.

4. Prensky predice que las personas en todo el mundo estarán conectadas a la AORTA (Acceso Siempre en Tiempo Real, por sus siglas en inglés), un término acuñado por Mark Anderson, el director de Strategic News Service, que se especializa en noticias de tecnología. En el ámbito en el que nos devolvemos profesionalmente que es el mundo de la comunicación es necesario que conocer los gustos y preferencias de esta nueva generación para elaborar campañas y estrategias "Social Media" adecuadas ya que tiene una diferencia notable en la utilización de las tecnologías.

5. Los resultados de la presente investigación será la primera de futuras investigaciones que irán encaminadas al área comunicación visual.

\section{Referencias}

Anglemana, S. (2010). Uses and Gratifi cations and Internet Profiles: A Factor Analysis. Is Internet Use 
and Travel to Cyberspace Reinforced by Unrealized Gratifications? Recuperado el 5 de enero del 2014, de http://www.jrily.com/LiteraryI1lusions/InternetGratificationStudyIndex.html

Aportaciones y conclusiones de plena rios, foros y coloquios. Congreso Internacional de Educación Mediática y Competencia Digital (2011). Segovia, España. Disponible en: http://www.educacionmediatica.es/congreso2011/documen$\mathrm{t} \quad \mathrm{o} \quad \mathrm{s} / \mathrm{C} \quad \mathrm{o} \quad \mathrm{n}$ clusiones-y-aportaciones-de-plena rios-foros-y-coloquios.pdf

Area, M., Gutiérrez, A., \& Vidal, F. (2012). Alfabetización digital y competencias informacionales. Madrid: Fundación Telefónica. Disponible en: https://ddv.ull.es/users/manarea/public/libro_Alfabetizacion_digital.pdf

Avello, R., \& Martín, I. (2008). El

Software Libre en la educación a distancia. Selección de Herramientas. Quaderns Digitals. Disponible en: http://dialnet.unirioja.es/ser$\mathrm{v} 1 \mathrm{et} / \mathrm{articu} 1$ o ? c o d i g o $=2875297$ \& o r den $=189851 \&$ info $=$ link

Boschma, J. (2010): Generación Einstein. Más listos, más rápidos $\mathrm{y}$ más sociables. Barcelona: Ediciones Gestión 2000.

Cabero, J. (2006). Bases pedagógicas del e-learning. Revista de Universidad y Sociedad del Conocimiento.
Disponible en: http://www.uoc.edu/rusc/3/1/dt/esp/cabero.pdf

Del Río, J. (2011): Atlas de la brecha digital, España 2007. Recuperado el 10 de octubre de 2014, de http://www.esnips.com/doc/cb40a03b-cf3d-4869-9ed6

Domingo, C. (2009): Digital Natives, Digital Immigrants and the News Generations. Recuperado el 23 de octubre de 2014, de http://www.unpocodetodo.com/2008/07/18/digital-immi$\begin{array}{llllllllllllll} & \mathrm{r} & \mathrm{r} & \mathrm{a} & \mathrm{n} & \mathrm{t} & \mathrm{s} & - & \mathrm{d} & \mathrm{i} & -\end{array}$ gital-natives-and-thenewe

Eighmey, J., \& McCordb, L. (1998):

Adding value in the information age: Uses and gratifications of sites on the world-wide web. Journal of Business Research, 41 (3), 187-194.

Ferreiro Ramón, F. (2011). El reto de la educación del siglo XXI: la generación N. Apertura. Revista de innovación educativa, 6 (5), 72-85.

Fleming, P. (2012). La Ciberesfera, una teoría en plena expansión. Recuperado el 08 de octubre de 2015 , de http://www.icemd.com/area-entra$\mathrm{da} /$ articulos/consultaart.asp?I$\mathrm{d}=107$

Freire, J. (2011). ¿Quiénes son los nativos digitales?, y ¿por qué? Recuperado el 10 de octubre de 2015, de Nómada. Reflexiones personales e 
información sobre la sociedad y el conocimiento abiertos: http://nomada.blogs.com/jfreire/2007/10/quines-son-los.html

Giussani, B. (2010). A Typology of Infor mation and Communication Technology Users. Recuperado el 23 de noviembre de 2015, de Pew Internet \& American Life Project: http://www.pewinternet.org/

González, N. (2012). Alfabetización para una cultura social, digital, mediática y en red. Revista Española de Documentación Científica. Disponible en: http://redc.revistas.csic.es/index.php/redc/article/view/743/824

Guzmán, L. (2010). Sintetizador de voz para la enseñanza de la lectura a niños mexicanos. Recuperado el 25 de agosto de 2014, de catarina.udlap.mx: http://catarina.udlap.mx/u_dl_a/tales/documen-

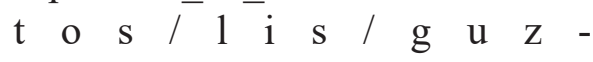
man_a_ma/capitulo1.pdf

Henríquez, P. (2012). Nativos digitales: aproximación a los patrones de consumo y hábitos de uso de internet, videojuegos y celulares. Revista Educación y Pedagogía 24(62) pp. 145-156. Disponible en: http://aprendeenlinea.udea.edu.co/revistas/in$\mathrm{d}$ e x . p h p / r e v i s taeyp/article/view/14200/12543

Manicini, P. (2009). Todos somos migrantes digitales. Recuperado el
12 de octubre de 2015, de http://www.amphibia.com.ar/todos-somos-migrantes-digitales/

Morduchowicz, R. (2008): La Generación multimedia. Significados, consumos. Buenos Aires: Paidós.

Palfrey, J. \& Gasser, U. (2008). Born Digital. New York: Basic Book.

Prensky, M. (2001). Digital Natives, Digital Immigrants. On the Horizon 9 (5).

Prensky, M. (2010). Nativos e inmigran tes digitales. Guayaquil: Albatros

Ruggiero, T. (2010). Uses and gratifica tions theory in the 21 st century. Mass Communication \& Society 3 , 3-37.

Tapscott. (2009). Grown up digital. Canada: MacrocomiCX

Vilches, L. (2011). La Migración Digital. Barcelona: Gedisa Editorial. 